\title{
Recent Updates in the Social and Environmental Determinants of Sleep Health
}

\author{
Lauren Hale $^{1} \cdot$ Erin Emanuele $^{1} \cdot$ Sarah James $^{2}$
}

Published online: 1 October 2015

(C) Springer International Publishing AG 2015

\begin{abstract}
In this brief review article, we provide an overview of recent (since 2010) scientific contributions to our understanding of the social and environmental determinants of sleep health. In particular, we focus on three areas where we saw the most contributions to the determinants of sleep health among children, adolescents, and adults. First, studies of neighborhood context and sleep health find that sleep quality and quantity are lower in disadvantaged neighborhoods. These negative associations are often stronger for women than for men. Second, family factors matter for sleep health. Children from families with more parental resources sleep better than do children from families without such resources. Adults with children sleep less than those without, and work-family conflict is an impediment to good sleep. Third, media use is problematic for sleep health. Around the world, higher levels of screen media use are associated with lower quality and quantity of sleep. Future research on the social and environmental determinants of sleep health will grow out of these three areas of current research. In addition, we anticipate new research in the international realm and in the area of interventions designed to improve the population's sleep health.
\end{abstract}

Keywords Sleep $\cdot$ Health $\cdot$ Social determinants ·

Environmental determinants $\cdot$ Media use

This article is part of the Topical Collection on Sleep Epidemiology

Lauren Hale

laurenhale@gmail.com

1 Program in Public Health, Stony Brook University, HSC Level 3, Room 071, Stony Brook, NY 1194-8338, USA

2 Sociology and Social Policy, Office of Population Research, Princeton University, 227 Wallace Hall, Princeton, NJ 08544, USA

\section{Introduction}

In the past decade, the study of sleep health has been enriched through the work of sleep researchers, social scientists, and epidemiologists interested in understanding the social and environmental determinants of sleep patterns around the world. One highlight from this research is the discovery that socioeconomic factors, such as race/ethnicity and education level, predict sleep duration and sleep quality [1-3]. To keep the scope of this article focused on current findings, we limit our review update to include articles published since 2010. We are motivated to study the social and environmental determinants of sleep because they offer a potential explanation for disparities in health and well-being. In addition, explicating the social factors that determine sleep helps people-from policy makers to parents - improve sleep patterns through interventions that target social and environmental threats to good sleep.

In the process of reviewing the literature on the social and environmental determinants of sleep health, we identified three major advances in the field: (1) neighborhood context and sleep, (2) family factors and sleep (among both children and adults), and (3) media use and sleep. We summarize the recent literature on these topics concisely below.

\section{Neighborhood Context and Sleep}

Since 2010, the scientific literature on neighborhood context and sleep has grown substantially. These studies find that a range of sleep measures, including sleep quality, sleep duration, insomnia symptoms, and sleep latency, are adversely associated with living in neighborhoods that are characterized by disorder, low social cohesion, and low socioeconomic status. These patterns have been observed among adults 
[4-11], adolescents [12, 13], and, to a lesser extent, children [14].

The association of neighborhood quality and adults' sleep health has been documented in both domestic [4-7] and international [8-11] settings. In the United States of America (USA), a study of 371 Latino adults living in a neighborhood with few socioeconomic resources found that community disorder and building issues, such as concerns about litter, security, lighting, and cleanliness, are associated with impaired sleep quality and sleep disruptions [5]. There is mixed evidence on the relationship between neighborhood factors and insomnia. While a cross-sectional study shows no significant association between neighborhood characteristics and insomnia [6], a longitudinal analysis of 7231 American adults aged 51 years of age and older finds that there is a significant association between neighborhood physical disorder (e.g., vandalism/graffiti, feeling safe alone after dark, and cleanliness) and insomnia symptoms such as difficulty falling asleep [4]. Additionally, another study replicates this pattern and demonstrates that sleep quality mediates the association between neighborhood quality and self-reported health [7].

Studies of adults living outside of the USA show similar patterns to those identified in the USA. Most studies of neighborhood factors and sleep quality outside of the USA have focused on neighborhood safety. For example, one study using cross-sectional data from Mexico, Ghana, South Africa, India, China, and Russia finds that perceptions of neighborhood safety predict adverse sleep outcomes, with the strongest associations in Russia and China [8]. Similarly, feelings of being unsafe at home predict poor sleep quality among Argentinian adults, and this association fully attenuates the association between perceived neighborhood safety and sleep [9]. Interventions to improve sleep are also of international concern; a program evaluation study of the sleep quality of Argentinian adults found that a transition from residing in slums to improved living conditions improved sleep quality [10].

Adverse associations between neighborhood factors and sleep outcomes are also found among children and adolescents [12-14]; however, the relationship has not been evaluated as extensively as for adults [12]. In an analysis of 1226 mother-child pairs in a prospective pre-birth cohort, infants living in the most urban areas slept significantly less per day than infants in the least urban areas [14]. Additionally, a crosssectional $(n=263)$ and longitudinal assessment $(n=7945)$ of teens living in the USA examines sleep outcomes in relation to two aspects of community disadvantage: hopelessness and violence exposure. Factors characteristic of vulnerable neighborhoods are negatively associated with sleep outcomes for girls, but not for boys [12].

In evaluating the relationship between neighborhoods and sleep health, several studies identify the importance of one demographic characteristic-sex-in these associations. Three studies included in this review found inverse associations between neighborhood factors and sleep outcomes among women and men $[9,11,12]$. There are significant associations between neighborhood disadvantage [11], feelings of insecurity [9], and hopelessness and violence exposure [12] and sleep outcomes that hold for women but not for men.

Although recent additions to the literature on neighborhood factors and sleep have made important progress, this literature also faces several limitations. Many of these studies are crosssectional and thus are subject to temporal ambiguity (e.g., possibility of reverse causality), which further limits the ability to infer causality inherent to observational studies in general. Despite the increasing attention to sex differences in the association of neighborhood factors with sleep outcomes, many studies do not explore this important area of variation. Given these limitations, future research should utilize longitudinal data in order to examine causal processes and underlying mechanisms and be particularly sensitive to sex differences.

\section{Family Structure, Household Factors, and Sleep}

\section{Children's Sleep}

Family factors and social context play a role in shaping sleep patterns and sleep behaviors throughout the life course, beginning at birth. For example, maternal depression is particularly problematic for infants' sleep patterns. Postpartum depression when the child is 5 months old is associated with more infant nighttime awakenings at 9 months old [15]. Maternal depression and anxiety when the child is 6 or 12 months old is associated with concurrent infant sleep problems, and maternal anxiety when the child is 6 months old is associated with more crying at bedtime 6 months later [16]. The association of maternal depression and infants' sleep among 1- to 24-monthold infants may come about because mothers who are depressed or worried about their infants' nighttime needs spend more time with their infants during the night, and maternal nighttime presence predicts more infant awakenings. Video recordings of these mother-child interactions indicate that depressed mothers are excessively attentive to their infants during the night [17]. In contrast, in-home video observations of mothers and infants ages 1 month to 2 years at bedtime suggest that those mothers who have been coded as emotionally available have infants with fewer night awakenings and sleep difficulties [18].

Family factors including the nature of parents' relationships and physical elements of the home are associated with preschoolers' sleep patterns. Marital instability at 9 months is associated with higher levels of child bedtime resistance at 18 months [19] and difficulty falling and staying asleep at 4.5 years [20]. Also, young children who sleep in a room too bright, loud, cold, or hot sleep on average 
27 fewer minutes per night and fall asleep 22 min later on weeknights [21].

The association of family factors with the sleep of school age children has been investigated in detail in the Auburn University Sleep Study, which follows 250 children in nonurban areas of the southeast from age 9 to 11 . The study finds, broadly, that children from families with lower income-toneeds ratios sleep less $[22,23]$ and have more actigraphyassessed epochs of sleep with movement each night [24] than do those from more advantaged families. Children of depressed parents spend fewer minutes in bed and children of depressed mothers have greater activity during sleep than children without depressed parents [25]. Family conflict is also associated with children's sleep quality. Sleep efficiency and the number of long wake episodes per night at age 10 intervene in the association of parent-child conflict at age 9 and problem behavior in children at age 11 [26]. Children whose parents have high marital conflict at age 9 have more sleep problems at age 10 [27] and age 11 [24] than children of parents with less marital conflict.

Evidence from other studies support the finding that family factors matter for children's sleep in elementary school. Moreeducated parents have more accurate knowledge about healthy sleep practices than do less-educated parents, and children of parents with more accurate sleep knowledge have longer sleep durations than those of parents with less accurate knowledge [28]. Also, parental financial problems are associated with higher levels of parent-reported sleep problems in children [29].

Family environments continue to matter for sleep patterns in the teenage and young adult years. There is concordance between the sleep, bed, and wake times of parents and teenagers [30]. Compared to 14- to 17-year-olds from two-parent households, teens from single-parent households have lower sleep efficiency during the week and shorter sleep duration on the weekend [31]. In addition, seventh graders in families with low socioeconomic status go to bed later and have shorter sleep durations during the school week and have more variable sleep patterns than more advantaged teens [32]. During the transition to adulthood, family relationships are associated with sleep patterns. Undergraduate students who engaged in regular family activities during childhood report better sleep quality than those who did not have this type of family interaction [33].

\section{Adults' Sleep}

Being a parent is negatively associated with adults' sleep. Frequent insufficient sleep increases linearly with the number of co-resident children for men and women who are or have been married and never-married women [34]. Compared to non-parents, parents sleep an average of 13 fewer minutes per night per child less than age 2 years old, nine fewer minutes per child when children are 2-5 years old, and four fewer minutes per child when children are 6-18 years old; parents are also more likely to feel sleepy or doze during then day than non-parents [35]. Children's sleep is also problematic for parents' sleep. For mothers of 6- to 11-month-old infants, short infant nighttime sleep duration is associated with higher odds of short maternal sleep duration [36].

Conflict between work and family is associated with lower quality [37-39] and quantity [38] of sleep. These effects are largest when work and family demands are highest [40] and tend to persist: high work-family conflict is associated with higher frequency of insufficient sleep 2 years later [39]. There is compelling evidence that this relationship may be causal; a randomized-controlled workplace intervention to reduce work-family conflict increased actigraphy-assessed sleep duration and reduces self-reported sleep insufficiency 1 year later as compared to a control group [41].

Co-resident partners may either contribute to or help resolve sleep difficulties. Among married or cohabiting couples, psychological conflict with romantic partners is associated with poorer quality sleep [42]. Additionally, interpersonal distress is associated with worse sleep quality and more REM sleep; among insomniacs, interpersonal distress is associated with higher pre-sleep arousal, more severe insomnia, shorter sleep duration, and, counterintuitively, shorter sleep onset [43]. In contrast, partners with sleep apnea report that their spouses are crucial in alerting them to their sleep problems and pushing them to get treatment [44].

Marital status matters for sleep. In a nationally representative US sample, being married is broadly associated with lower odds of very short or very long sleep durations [3]. Similarly, frequent insufficient sleep is more common among previously married than never or currently married men and women [34]. In another nationally representative sample, married people have fewer problems with maintaining sleep than those who are divorced but report snoring more than those who are widowed, separated, or never married [45].

The relationship between family and household factors and the sleep of children and adults has made significant progress since 2010 but faces some limitations. Despite increasing attention to longitudinal studies of children's sleep (e.g., the Auburn University Sleep Study), there are few long-term evaluations of adolescent and adult sleep patterns. Most studies rely on selfreported measures of sleep. Future work should make use of longitudinal data on adolescent and adult sleep, utilizing independent and objective measures of sleep outcomes. Additionally, few studies evaluated here paid particular attention to the role of fathers, as compared to mothers, in children's sleep or how the increasing complexity of family structure impacts sleep across the life course. 


\section{Screen Use and Sleep}

The use of screen media is increasingly linked to sleep problems. For adults, the negative association between screen use and sleep duration, timing, and quality has been verified in recent literature [46-50]. One set of studies evaluates the biological mechanisms by which screen media use impacts sleep. In a randomized crossover study, the use of light emitting ereaders, defined as electronic handheld devices, decreased melatonin levels and delayed the participants' ability to fall asleep as compared to reading printed books. The next morning, those who had used light emitting e-readers were less alert than those who read printed books [46]. Similarly, the use of LED-lit consoles interferes with melatonin secretion in healthy males ages 20 to 30 [47]. Screen media use is also associated sleep timing and quality. Adults who report more than $6 \mathrm{~h}$ of screen time per day are more likely to have delayed bedtimes and difficulty staying asleep than adults who use screens for less than $2 \mathrm{~h}$ per day [50].

For children and adolescents, the association between screen time and sleep outcomes is similar to that of adults: more screen time is worse for sleep outcomes. In a systematic review of 67 studies of screen time and sleep among children and adolescents, $90 \%$ of studies found an association between screen time and an adverse sleep outcome [51].

Studies conducted in multiple other countries outside the USA also show that increased screen time is associated with decreased sleep duration [52-62] and delayed bedtime [56, $58,63,64]$. For instance, a cross-sectional study of 9846 Norwegian adolescents finds that use of electronic devices during the day and night is associated with an elevated risk of shorter sleep duration, among other sleep measures [56]. In Thailand, exposure to screens at 1 year of age is associated with 28 fewer minutes of sleep per night than infants who were not exposed to screens when they were 1 year old [60]. However, there is a bidirectional association between screen use and sleep duration, making it difficult to ascertain whether poor quality or inadequate sleep leads to increased screen time or whether screens themselves lead to worse sleep [57].

Beyond screen media use, the presence and number of screens in the bedroom is also associated with poor sleep quality $[65,66]$, delayed bedtime [58], and decreased sleep duration $[54,58,61,66]$ among children and adolescents. For example, 9- to 12-year-old children with screens in their bedrooms sleep less than peers without screens. On average, a small screen, such as a smartphone, is associated with 20.6 fewer minutes of sleep per night; a television is associated with 18 fewer minutes of sleep per night [66]. While another study did not find a significant association between the number of screens present in a child's room and sleep duration, it established that children with two or more screens in their room have lower sleep efficiency [65]. Finally, a longitudinal study of 353 Finnish students suggests that there are sex differences in the association of screen time and sleep problems [58].

Although mounting evidence suggests an inverse association between screen use and presence and poor sleep among adults, adolescents, and children, these studies face some limitations. These studies typically are observational, utilize self-reported data, and consider a limited range of media types. In addition, most studies do not examine specific media content or consider illumination from new types of bright displays, such as tablets. Future studies can address these limitations by using study designs that are better able to assess causality (e.g., cohort studies and experimental intervention trials) and should include independent or objective measures of media use and sleep. Other types of media, such as tablets, should be included in media use as technology develops. Finally, no studies evaluated here consider the differential impact of varying types of media viewing on sleep outcomes.

\section{Conclusion}

As summarized in this review, the research on the social and environmental determinants of sleep health has grown rapidly since 2010, with significant progress in assessing the roles of neighborhoods, families, and media use for sleep outcomes. This literature increasingly evaluates the specific mechanisms and potential consequences of disparate sleep patterns at the population level. While this review of the literature is not comprehensive, it provides sufficient breadth to highlight three key recommendations for future research on the social determinants of sleep. First, it is crucial that researchers improve the measurement of sleep outcomes and social and environmental exposures in order to best specify which factors are most important for specific sleep outcomes. Second, study designs suited to establishing causal relationships - for example, longitudinal studies and experiments - can identify the causal pathways by which social and environmental factors impact sleep health. Finally, sleep researchers, social scientists, and epidemiologists should identify the policy implications of their work and potential interventions that would improve sleep health.

Acknowledgments Research reported in this article was supported by the Eunice Kennedy Shriver National Institute for Child Health and Human Development and the National Heart, Lung, and Blood Institute of the National Institutes of Health under award numbers R01HD073352 and R01HL122460.

The content is solely the responsibility of the authors and does not necessarily represent the official views of the National Institutes of Health. 


\section{Compliance with Ethics Guidelines}

Conflict of Interest Lauren Hale, Erin Emanuele, and Sarah James declare that they have no conflict of interest

Human and Animal Rights and Informed Consent This article does not contain any studies with human or animal subjects performed by any of the authors.

\section{References}

1. Hale L, Do DP. Racial differences in self-reports of sleep duration in a population-based study. Sleep. 2007;30(9):1096.

2. Williams NJ, Grandner MA, Snipes SA, Rogers A, Williams O, Airhihenbuwa C, et al. Racial/ethnic disparities in sleep health and health care: importance of the sociocultural context. Sleep Health. 2015;1(1):28-35.

3. Whinnery J, Jackson N, Rattanaumpawan P, Grandner MA. Short and long sleep duration associated with race/ethnicity, sociodemographics, and socioeconomic position. Sleep. 2014;37(3):601.

4. Chen-Edinboro LP, Kaufmann CN, Augustinavicius JL, Mojtabai R, Parisi JM, Wennberg A, et al. Neighborhood physical disorder, social cohesion, and insomnia: results from participants over age 50 in the Health and Retirement Study. Int Psychogeriatr. 2015;27(02): 289-96.

5. Chambers EC, Pichardo MS, Rosenbaum E. Sleep and the housing and neighborhood environment of urban Latino adults living in low-income housing: the AHOME Study. Behavioral sleep medicine. 2014(ahead-of-print):1-16.

6. DeSantis AS, Roux AVD, Moore K, Baron KG, Mujahid MS, Nieto FJ. Associations of neighborhood characteristics with sleep timing and quality: the multi-ethnic study of atherosclerosis. Sleep. 2013;36(10):1543.

7. Hale L, Hill TD, Friedman E, Nieto FJ, Galvao LW, Engelman CD, et al. Perceived neighborhood quality, sleep quality, and health status: evidence from the Survey of the Health of Wisconsin. Soc Sci Med. 2013;79:16-22.

8. Hill TD, Trinh HN, Wen M, Hale L. Perceived neighborhood safety and sleep quality: a global analysis of six countries. Sleep Medicine. 2014.

9. Simonelli G, Patel SR, Rodríguez-Espínola S, Pérez-Chada D, Salvia A, Cardinali DP, et al. The impact of home safety on sleep in a Latin American country. Sleep Health. 2015.

10. Cardinali DP, Simonelli G, Rodríguez Espínola S, Salvia A, PérezChada D, Vigo D. Sleep, slums and shelter: impact of a slumhousing upgrading program. Proceedings of the Working Group in Bread, Brain, Education and Poverty. 2013:1-14.

11. Bassett E, Moore S. Neighbourhood disadvantage, network capital and restless sleep: is the association moderated by gender in urbandwelling adults? Soc Sci Med. 2014;108:185-93.

12. Umlauf MG, Bolland AC, Bolland KA, Tomek S, Bolland JM. The effects of age, gender, hopelessness, and exposure to violence on sleep disorder symptoms and daytime sleepiness among adolescents in impoverished neighborhoods. Journal Youth Adolesc. 2015;44(2):518-42.

13. Umlauf MG, Bolland JM, Lian BE. Sleep disturbance and risk behaviors among inner-city African-American adolescents. J Urban Health. 2011;88(6):1130-42.

14. Bottino CJ, Rifas-Shiman SL, Kleinman KP, Oken E, Redline S, Gold $\mathrm{D}$, et al. The association of urbanicity with infant sleep duration. Health Place. 2012;18(5):1000-5.
15. Gress-Smith JL, Luecken LJ, Lemery-Chalfant K, Howe R. Postpartum depression prevalence and impact on infant health, weight, and sleep in low-income and ethnic minority women and infants. Matern Child Health J. 2012;16(4):887-93.

16. Goldberg WA, Lucas-Thompson RG, Germo GR, Keller MA, Davis EP, Sandman CA. Eye of the beholder? Maternal mental health and the quality of infant sleep. Soc Sci Med. 2013;79:101-8.

17. Teti DM, Crosby B. Maternal depressive symptoms, dysfunctional cognitions, and infant night waking: the role of maternal nighttime behavior. Child Dev. 2012;83(3):939-53.

18. Teti DM, Kim B-R, Mayer G, Countermine M. Maternal emotional availability at bedtime predicts infant sleep quality. J Fam Psychol. 2010;24(3):307.

19. Mannering AM, Harold GT, Leve LD, Shelton KH, Shaw DS, Conger RD, et al. Longitudinal associations between marital instability and child sleep problems across infancy and toddlerhood in adoptive families. Child Dev. 2011;82(4):1252-66.

20. Rhoades KA, Leve LD, Harold GT, Mannering AM, Neiderhiser JM, Shaw DS, et al. Marital hostility and child sleep problems: direct and indirect associations via hostile parenting. J Fam Psychol. 2012;26(4):488.

21. Wilson KE, Miller AL, Lumeng JC, Chervin RD. Sleep environments and sleep durations in a sample of low-income preschool children. J Clin Sleep Med JCSM Off Publ Am Acad Sleep Med. 2014;10(3):299.

22. El-Sheikh M, Kelly RJ, Sadeh A, Buckhalt JA. Income, ethnicity, and sleep: coping as a moderator. Cult Divers Ethn Minor Psychol. 2014;20(3):441

23. El-Sheikh M, Tu KM, Erath SA, Buckhalt JA. Family stress and adolescents' cognitive functioning: sleep as a protective factor. J Fam Psychol. 2014;28(6):887.

24. Kelly RJ, El-Sheikh M. Marital conflict and children's sleep: reciprocal relations and socioeconomic effects. J Fam Psychol. 2011;25(3):412.

25. El-Sheikh M, Kelly RJ, Bagley EJ, Wetter EK. Parental depressive symptoms and children's sleep: the role of family conflict. J Child Psychol Psychiatry. 2012;53(7):806-14.

26. Kelly RJ, Marks BT, El-Sheikh M. Longitudinal relations between parent-child conflict and children's adjustment: the role of children's sleep. J Abnorm Child Psychol. 2014;42(7):1175-85.

27. El-Sheikh M, Hinnant JB, Erath SA. VI. Marital conflict, vagal regulation, and children's sleep: a longitudinal investigation. Monogr Soc Res Child Dev. 2015;80(1):89-106.

28. Owens JA, Jones C. Parental knowledge of healthy sleep in young children: results of a primary care clinic survey. J Dev Behav Pediatr. 2011;32(6):447-53.

29. Lundahl A, Nelson TD, Van Dyk TR, West T. Psychosocial stressors and health behaviors examining sleep, sedentary behaviors, and physical activity in a low-income pediatric sample. Clin Pediatr. 2013;52(8):721-9.

30. Fuligni AJ, Tsai KM, Krull JL, Gonzales NA. Daily concordance between parent and adolescent sleep habits. J Adolesc Health. 2015;56(2):244-50.

31. Troxel WM, Lee L, Hall M, Matthews KA. Single-parent family structure and sleep problems in black and white adolescents. Sleep Med. 2014;15(2):255-61.

32. Marco CA, Wolfson AR, Sparling M, Azuaje A. Family socioeconomic status and sleep patterns of young adolescents. Behav Sleep Med. 2012;10(1):70-80.

33. Malatras J, Luft I, Sokolowski K, Israel A. Family stability as a moderator of the relationship between family life changes and sleep behavior. 2012.

34. Chapman DP, Wheaton AG, Perry GS, Sturgis SL, Strine TW, Croft JB. Household demographics and perceived insufficient sleep among US adults. J Community Health. 2012;37(2):344-9. 
35. Hagen EW, Mirer AG, Palta M, Peppard PE. The sleep-time cost of parenting: sleep duration and sleepiness among employed parents in the Wisconsin Sleep Cohort Study. American journal of epidemiology. 2013:kws246.

36. Demirci JR, Braxter BJ, Chasens ER. Breastfeeding and short sleep duration in mothers and 6-11-month-old infants. Infant Behav Dev. 2012;35(4):884-6.

37. Allen TD, Kiburz KM. Trait mindfulness and work-family balance among working parents: the mediating effects of vitality and sleep quality. J Vocat Behav. 2012;80(2):372-9.

38. Crain TL, Hammer LB, Bodner T, Kossek EE, Moen P, Lilienthal $\mathrm{R}$, et al. Work-family conflict, family-supportive supervisor behaviors (FSSB), and sleep outcomes. J Occup Health Psychol. 2014;19(2): 155

39. Jacobsen HB, Reme SE, Sembajwe G, Hopcia K, Stoddard AM, Kenwood C, et al. Work-family conflict, psychological distress, and sleep deficiency among patient care workers. Work Health Saf. 2014;62(7):282-91.

40. Barnes CM, Wagner DT, Ghumman S. Borrowing from sleep to pay work and family: expanding time-based conflict to the broader nonwork domain. Pers Psychol. 2012;65(4):789-819.

41. Olson R, Crain TL, Bodner TE, King R, Hammer LB, Klein LC, et al. A workplace intervention improves sleep: results from the randomized controlled work, family, and health study. Sleep Health. 2015;1(1):55-65.

42. El-Sheikh M, Kelly R, Rauer A. Quick to berate, slow to sleep: interpartner psychological conflict, mental health, and sleep. Health Psychol. 2013;32(10):1057.

43. Gunn HE, Troxel WM, Hall MH, Buysse DJ. Interpersonal distress is associated with sleep and arousal in insomnia and good sleepers. J Psychosom Res. 2014;76(3):242-8.

44. Henry D, Rosenthal L. "Listening for his breath:" The significance of gender and partner reporting on the diagnosis, management, and treatment of obstructive sleep apnea. Soc Sci Med. 2013;79:48-56.

45. Grandner MA, Petrov MER, Rattanaumpawan P, Jackson N, Platt A, Patel NP. Sleep symptoms, race/ethnicity, and socioeconomic position. J Clin Sleep Med JCSM Off Publ Am Acad Sleep Med. 2013;9(9):897.

46. Chang A-M, Aeschbach D, Duffy JF, Czeisler CA. Evening use of light-emitting eReaders negatively affects sleep, circadian timing, and next-morning alertness. Proceedings of the National Academy of Sciences. 2015:201418490.

47. Bues M, Pross A, Stefani O, Frey S, Anders D, Späti J, et al. LEDbacklit computer screens influence our biological clock and keep us more awake. J Soc Inf Disp. 2012;20(5):266-72.

48. Wu X, Tao S, Zhang Y, Zhang S, Tao F. Low physical activity and high screen time can increase the risks of mental health problems and poor sleep quality among Chinese college students. PLoS One. 2015;10(3):e0119607.

49. Fossum IN, Nordnes LT, Storemark SS, Bjorvatn B, Pallesen S. The association between use of electronic media in bed before going to sleep and insomnia symptoms, daytime sleepiness, morningness, and chronotype. Behav Sleep Med. 2014;12(5):343-57.

50. Vallance JK, Buman MP, Stevinson C, Lynch BM. Associations of overall sedentary time and screen time with sleep outcomes. Am J Health Behav. 2015;39(1):62-7.
51. Hale L, Guan S. Screen time and sleep among school-aged children and adolescents: a systematic literature review. Sleep medicine reviews. 2014

52. Arora T, Broglia E, Thomas GN, Taheri S. Associations between specific technologies and adolescent sleep quantity, sleep quality, and parasomnias. Sleep Med. 2014;15(2):240-7.

53. Arora T, Hussain S, Lam KBH, Yao GL, Thomas GN, Taheri S Exploring the complex pathways among specific types of technology, self-reported sleep duration and body mass index in UK adolescents. Int J Obes. 2013;37(9):1254-60.

54. Cespedes EM, Gillman MW, Kleinman K, Rifas-Shiman SL, Redline S, Taveras EM. Television viewing, bedroom television, and sleep duration from infancy to mid-childhood. Pediatrics. 2014;133(5):e1163-e71.

55. Chahal H, Fung C, Kuhle S, Veugelers PJ. Availability and nighttime use of electronic entertainment and communication devices are associated with short sleep duration and obesity among Canadian children. Pediatr Obes. 2013;8(1):42-51.

56. Hysing M, Pallesen S, Stormark KM, Jakobsen R, Lundervold AJ, Sivertsen B. Sleep and use of electronic devices in adolescence: results from a large population-based study. BMJ Open. 2015;5(1):e06748.

57. Magee CA, Lee JK, Vella SA. Bidirectional relationships between sleep duration and screen time in early childhood. JAMA Pediatr. 2014;168(5):465-70.

58. Nuutinen T, Ray C, Roos E. Do computer use, TV viewing, and the presence of the media in the bedroom predict school-aged children's sleep habits in a longitudinal study? BMC Public Health. 2013;13(1):684.

59. Mak YW, Wu CST, Hui DWS, Lam SP, Tse HY, Yu WY, et al Association between screen viewing duration and sleep duration, sleep quality, and excessive daytime sleepiness among adolescents in Hong Kong. Int J Environ Res Public Health. 2014;11(11): 11201-19.

60. Vijakkhana N, Wilaisakditipakorn T, Ruedeekhajorn K, Pruksananonda C, Chonchaiya W. Evening media exposure reduces night-time sleep. Acta Paediatrica. 2014.

61. Garmy P, Nyberg P, Jakobsson U. Sleep and television and computer habits of Swedish school-age children. J Sch Nurs. 2012;28(6):469-76

62. Lemola S, Perkinson-Gloor N, Brand S, Dewald-Kaufmann JF, Grob A. Adolescents' electronic media use at night, sleep disturbance, and depressive symptoms in the smartphone age. Journal of youth and adolescence. 2014:1-14.

63. Ogunleye AA, Voss C, Sandercock GR. Delayed bedtime due to screen time in schoolchildren: importance of area deprivation. Pediatrics International. 2014.

64. Kubiszewski V, Fontaine R, Rusch E, Hazouard E. Association between electronic media use and sleep habits: an eight-day follow-up study. Int J Adolesc Youth. 2014;19(3):395-407.

65. Chaput J-P, Leduc G, Boyer C, Bélanger P, LeBlanc AG, Borghese $\mathrm{MM}$, et al. Electronic screens in children's bedrooms and adiposity, physical activity and sleep: do the number and type of electronic devices matter? Can J Public Health. 2014;105(4):e273-e9.

66. Falbe J, Davison KK, Franckle RL, Ganter C, Gortmaker SL, Smith $\mathrm{L}$, et al. Sleep duration, restfulness, and screens in the sleep environment. Pediatrics. 2015:peds. 2014-306. 